\title{
EL TIEMPO DE LA COMUNICACIÓN DISCURSIVA. LA SEGUNDA VOZ DEL CARNAVAL Y LAS ESTRATEGIAS DE LA INVERSIÓN
}

\section{THE TIME OF DISCOURSIVE COMMUNICATION. THE SECOND VOICE OF THE CARNAVAL AND INVERSION STRATEGIES}

\section{Paulo Damián Aniceto*}

\begin{abstract}
RESUMEN
Este artículo se propone relevar el lugar asignado por Mijaíl Bajtín a las relaciones entre el tiempo del enunciado y el tiempo de la comunicación discursiva. Los conceptos de conciencia, intención, creatividad ideológica y comprensión acuden a la delimitación de otros, estructurantes y decisivos, como el del tiempo de la interacción estratégica. La perspectiva dialógica de abordaje de la cultura popular nos sugiere aún discutir sobre la relación que se establece en el espacio semiótico agónico abierto entre dos dominios: lo ideológico y el tiempo de lo ideológico. La heteroglosia designa un campo de interacción de voces con proyectos estratégicos. Reconocerlo implica asumir la voz de la cultura popular como interactuante con otras voces en el tiempo de la lucha por la significación ideológica. La fecundidad del debate nunca consumado sobre el sujeto histórico del discurso nos invita a poner en tensión la noción de transformación con aquello que Balandier denomina estrategias de inversión. Exploramos, de esta forma, las preocupaciones de índole sociológica que atraviesan las reflexiones bajtinianas sobre el texto y el enunciado.

Palabras-clave: Mijaíl Bajtín; Estrategias de inversión; Espacio semiótico agónico.
\end{abstract}

\section{ABSTRACT}

This paper proposes to relieve the place that Mikhail Bakhtin assigns to relationships between enunciation's time and discoursive's time. The concepts of conscience, intention, ideological creativity and understanding come to the delimitation of other concepts, structurants and decisive, as the strategic interaction's time. The dialogical perspective approach to popular culture suggests us to discuss on relationship established in the open agonistic semiotic space between two domains: the ideological and ideological time. Heteroglossia designates a field of interaction of voices with strategic projects. To recognize this implies assuming the voice of popular culture as interacting with other voices in the time of the struggle for ideological significance. The fecundity of the never consummated discussion on the historical subject of discourse invites us to strain

\footnotetext{
* Universidad Nacional de Córdoba, Córdoba, Argentina. paulodamiananiceto@gmail.com http://dx.doi.org/10.1590/010318134799171841
} 
the notion of transformation with what Balandier called inversion strategies. We explore in this way, the concerns of sociological nature that cross Bakhtinian reflections on the text and enunciation.

Keywords: Mikhail Bakhtin; Inversion strategies; Agonistic semiotic space.

El pueblo no se excluye a sí mismo del mundo en evolución. También

él se siente incompleto; también él renace y se renueva con la muerte

(BAJTÍN, 1987 [1971], p. 17)

\section{INTRODUCCIÓN}

Una lectura detenida de la producción bajtiniana no podría soslayar algunos temas que estructuran el desarrollo reflexivo abocado a la bivocalidad y conclusividad de los enunciados. Ciertos temas recurren en conexión con la noción de totalidad y con la nunca completa cadena de comunicación discursiva. Unos conceptos acuden a la definición de otros, estructurantes y decisivos, como el del tiempo de la interacción enunciativa. Estos elementos constituyen el punto de apoyo de las reflexiones con las que Bajtín irrumpe en el dominio del análisis lingüístico tradicional. La perspectiva dialógica de abordaje de la cultura popular nos sugiere aún discutir sobre la relación entre el poder y el tiempo establecida en el espacio semiótico agónico. La heteroglósia designa un campo de interacción de voces con proyectos estratégicos. Reconocerlo implica asumir la festividad popular como una totalidad cuyo tiempo se inserta en el tiempo de la lucha por la significación ideológica. La alegría de la transformación es confrontada aquí a lo que Balandier entiende como estrategias de inversión.

Bajtín declara su sede en un campo intermedio, terreno de las interacciones posibles entre el análisis lingüístico, la filosofía del lenguaje y la historia literaria, que sobrepasan las fronteras de sus divisiones.

Bajtín, al advertir que "nos interesa aquí únicamente el problema de los textos verbales" (BAJTÍN, 1982 [1979], p. 295) no declara un enfoque lingüístico comprendido en los límites de la expresión, sino que sugiere la puesta en función del enunciado en relación con la vida del hombre y el tiempo. Podremos entender la centralidad que cobra esta concepción a condición de otorgarle el carácter de reflejo que Bajtín (1982 [1979]) le adjudica al enunciado. Designa un punto de entrada y llegada, la materialidad de una acción y una reacción, la manifestación material de la comprensión de lo ajeno. A partir del tiempo finito del enunciado, debemos suponer el tiempo de la interacción entre posiciones enunciativas. Quizás su aporte más 
preciado a la producción crítica posterior al estructuralismo sea su comprensión de la relación dialéctica y de sentido como traducciones lógicas de la relación dialógica y de agonismo. La situación histórica de la comunicación discursiva y la agencia del autor ocupan un lugar nodal. Solo esto puede aportarnos a asumir el espesor del principio enunciado por Bajtín: "el punto de partida sólo puede ser el texto" (BAJTÍN, 1982 [1979], p. 295).

\section{El tiempo y el problema del punto de vista}

El ingreso al debate sobre el tiempo y el carácter situado de las relaciones dialógicas nos exige recuperar la objeción bajtiniana a la noción saussureana de punto de vista.

La concepción del punto de vista aparece bien delimitada en el planteo del Curso de Linguística. Es fundada en el principio antisustancialista que sostiene que "las unidades significativas elementales deben ser buscadas al nivel de las estructuras y no al nivel de los elementos" (CASETTI, 1980, p. 281). Saussure (1945) centró su interés en el estudio de una estructura elemental de la lengua como un fenómeno eminentemente psíquico y descartó la utilidad de reparar en los fenómenos externos al sistema de la lengua. El punto de vista es creado por el objeto de estudio y contenido en el sistema de relaciones que le dan valor a los signos de la lengua.

Son precisamente los principios asumidos allí los que Bajtín objeta al asumir que "la representación es efectuada por la praxis histórica" (BAJTín, 1982 [1979], p. 296). La noción bajtiniana punto de vista es formulada como un hecho del plano de los hablantes y sus oyentes, de la posición enunciativa que tiene lugar y tiempo en el lugar y tiempo de la cadena de la comunicación discursiva. Eso explica la afirmación de que "la conversación puede ser registrada únicamente mediante un enfoque translingüístico, sólo cuando se los vea como 'visiones del mundo', 'puntos de vista"" (BAJTín, 1982 [1979], p. 311).

La noción punto de vista que establece que hay un elemento de prescripción del que un sistema de relaciones es portador resulta cuestionada. En su lugar, Bajtín asume aquella que lo presenta como el contenido del acto de un sujeto que crea un enunciado como marco (BAJTíN, 1982 [1979]) de otros enunciados. Al subrayar la relación dialógica de la heteroglosia como el espacio-tiempo de las posiciones enunciativas, nuestro autor asigna al punto de vista un carácter específico y abstractivo.

La distinción teórica entre el carácter específico del punto de vista bajtiniano y el objetivismo abstracto saussureano traduce una distinción metodológica. Aquí es donde debemos encuadrar la respuesta que Bajtín elabora sobre la posibilidad 
de estudiar científicamente fenómenos particulares: "por supuesto (...) el punto de partida de cualquier ciencia son las individualidades irrepetibles, y en toda su trayectoria la ciencia tiene que ver con ellas" (BAJTíN, 1982 [1979], p. 299).

Este trabajo se consagra a revistar los conceptos la comunicación discursiva situada y el plano de las posiciones enunciativas, como los temas que permiten comprender dos cuestiones transversales: el tiempo y el destinador superior.

\section{Tiempo, transformación y conciencia}

A comienzos del siglo $\mathrm{XX}$, el desarrollo de una filosofía del lenguaje en Europa se asentaba, predominantemente, sobre la base provista por la lingüística estructural saussureana. Una de las oposiciones que Saussure (1945) establece al asignar las oposiciones irremediables entre langue y parole podría ser denominada, con una simplicidad primaria, como individuo-sociedad. En la descripción de esta relación, la teoría del signo inmutable otorga un lugar central a la fuerza de la tradición que opera sobre el paso del tiempo. Éste se constituye en la lámina sobre la cual actúa la transmisión de las reglas (operada por la fuerza de la tradición) y en el factor bistórico (ANICETO, 2013) que condensa en cada estado de la lengua, el trayecto de lo inmutable y lo dispone como conjunto de elementos en relación de coexistencia.

Así, el principio de la inmutabilidad del sistema de la lengua se asienta sobre la idea de una fuerza social arrolladora que conserva sus reglas transmitiéndolas y de la sustitución de un estado del sistema de la lengua por otro. En este marco, ningún cambio ocurrido en el plano diacrónico ( $\mathrm{y}$, con esto, ningún cambio ocurrido) y evolutivo del tiempo será incorporado como tal, sino como un elemento más del estado de la lengua. El Curso de Linguística General establece una oposición fundamental que extiende sus efectos a las demás: el tiempo transitivo de la transformación vs. el tiempo garante de la tradición. El factor bistórico, la designación del tiempo de un estado de la lengua, sedimenta los cambios y los neutraliza, ubicándolos en el ejido de las relaciones inmutables del sistema.

Asumir, como lo hace Bajtín, el tiempo regenerador y la intersubjetividad como dimensiones constituyentes del medio ambiente de la conciencia, nos permite comprender el enunciado como unidad material situada, integrada a la cadena de comunicación discursiva y en vínculo con el hombre viviente. Desde una perspectiva bajtiniana, la oposición estructuralista fuerza de la tradición - voluntad individual no puede más que comprenderse como el principio sobre la impotencia que la conciencia individual y la evolución tienen frente a la masa de hablantes que garantizan la inmutabilidad en el tiempo. 
Saussure (1945), al desarrollar el hecho diacrónico de la evolución y el hecho sincrónico de la inmutabilidad, alude implícitamente al grado de compromiso de la lengua con los cambios en sus usos. Para él, los cambios producidos en el tiempo del habla provocan alteraciones sobre los elementos del sistema que no persisten en la lengua más que como efectos ruinosos. Del cambio sólo se registran vestigios que no pertenecen al hecho de transformación mismo sino al estado de un sistema. El ejemplo de la partida de ajedrez entre jugadores ininteligentes adjudica a los agentes de transformación posibles el papel de agentes de refuerzo de la tradición. La posibilidad de cambio y discontinuidad, en el estructuralismo saussureano, no es sólo opuesta al rol pasivo de la fuerza de la tradición sino absorbida por ella.

\section{Bajtín, la acción del hombre en la cultura}

La cadena de la comunicación se organiza por la posibilidad de respuesta que sigue a los enunciados conclusivos. En su contexto histórico de producción, este planteo se instauraba, en términos del mismo Bajtín, como una segunda voz. Sobre la imagen unívoca de las relaciones significantes de la cultura, se eleva la noción significación, como aquello no ajustable a molde, ni predecible, incapaz de imitarse a sí misma en el transcurso del tiempo. Diferenciada de la concepción saussureana de significado, es asignable al espacio material del transcurso de la vida del hombre y no al espacio imaginario de una entidad depositada en el cerebro de hablantes ininteligentes. La significación cobra relevancia en contacto con el carácter histórico de la comunicación discursiva: ni inmutabilidad de las relaciones sistémicas ni uniformidad de la expresión bajo el dominio de un principio de tradición.

La posibilidad de transformación no proviene de actos accidentales de hablantes que custodian las reglas, sino de marcos sociales de comprensión que rodean tanto al discurso propio como al discurso ajeno en el tiempo de la comunicación discursiva.

Es posible trazar arbitrariamente una línea común al aparato conceptual del estructuralismo y los argumentos que Bajtín empeña en criticarlos. La fuente del impulso crítico provenía del Seminario Kantiano que Bajtín conformaba junto a Valentín Voloshinov, Moisés Kagan, Pavel Medvedev.

En signo de ruptura, Bajtín desliza que "un enunciado aislado, con todo su carácter individual y creativo, no puede ser considerado como una combinación absolutamente libre de formas lingüísticas" (BAJTíN, 1982 [1979], p. 270). En estos términos, a la figura de un hablante impotente ante la fuerza de la tradición, el 
autor opone la de uno que crea marcos enunciativos partiendo de la comprensión del enunciado ajeno y de la autoobjetivación ${ }^{1}$.

La clave de entrada al desarrollo teórico bajtiniano sobre la cuestión del tiempo y el enunciado reside en comprender que lo ajeno y lo propio interactúan superando la oposición irremediable que el estructuralismo asignaba entre lo individual y lo social. El todo complejo e incompleto de la personalidad y la conciencia se constituye en la facultad de la expresividad y el estilo constituida intersubjetivamente.

\section{La personalidad del hombre en la historia de la cultura}

El todo mecánico de la personalidad se compone de elementos unidos sólo en el tiempo y el espacio (BAJTíN (1982 [1979]). Bajtín asigna a la personalidad un carácter histórico y define sus elementos constitutivos como momentos. Las partes del todo se deslizan en transcursos temporales de duración limitada, con fines y retomes, dando a un diálogo transitivo que es desplegado en espacios de tiempo común. El diálogo al interior de las fronteras de la personalidad es un diálogo inevitable entablado entre dos elementos (la vida y el arte) que no mantienen sólo una relación de contigüidad en la unidad mecánica, sino de responsabilidad.

El diálogo responsable es aquel sostenido por dos elementos de un todo mecánico actualizado en el hombre histórico, que debe responder ante el arte con las razones de su existencia y ante la vida con la praxis aprendida en el arte (BAJTÍN, (1982 [1979]). Ahora bien, tanto las razones existenciales como las elecciones estéticas del hombre de la cultura son impensadas sin la presencia interpelante de un otro. Con todo, el carácter dialógico e histórico de la constitución de la personalidad ofrece una réplica en escala del diálogo de las totalidades conclusivas (BAJTíN, 1982 [1979]) de la cultura.

\section{El hombre histórico, conciencia e intersubjetividad}

Una reflexión sobre el papel del tiempo y la historia en el pensamiento de Bajtín no podría ignorar que el principio de la personalidad responsable aparece con una función crítica. Al decir sobre el todo de la personalidad que sus momentos

\footnotetext{
${ }^{1}$ Tiempo después, Bourdieau (2001) reforzaría la idea de los efectos ideológicos implicados en el acto de abstraer el carácter histórico y simbólico de la formación de la lengua legítima en estructuras de dominación. En su crítica, el autor asegura que el estructuralismo saussureano ha olvidado (con efectos ideológicos) la correspondencia simbólica entre el sistema de oposiciones lingüísticas con un sistema de oposiciones sociales desiguales en el marco de un mercado lingüístico.
} 
"tienen que acomodarse juntos en la serie temporal de su vida" y "compenetrarse mutuamente", Bajtín (1982 [1979], p. 11) repone y cuestiona el asunto del predominio del plano sincrónico de análisis y la oposición sincronía-diacronía.

Los opuestos planteados por la lingüística formal eran traídos al debate sobre las posiciones enunciativas y los enunciados dialógicos. Lo diacrónico y lo sincrónico se convierten en dos planos que conviven plegados en la unidad de la personalidad. La vida y el arte son desarrolladas en transcursos de tiempo diferentes pero compenetradas en la exigencia recíproca de responsabilidad. La duración de una y otra se encuentran en la serie temporal de vida del hombre. "Cuando el hombre se encuentra en el arte, no está en la vida, y al revés" (BAJTíN, 1982 [1979], p. 11)

El hombre, podremos interpretar, es responsable por las prácticas de su tiempo. El tiempo del arte rendirá cuentas al tiempo de la vida, porque ambos tiempos se empalman en la unidad de la personalidad.

"El arte y la vida no son lo mismo, pero deben convertirse en mí en algo unitario, dentro de la unidad de mi responsabilidad" (BAJTíN, 1982 [1979], p. 11). El término bombre denomina, en definitiva, la unidad histórica de la personalidad constituida en un diálogo siempre en curso. El hombre de su tiempo es una totalidad que reconoce el trayecto de su devenir como la expectativa de nuevas relaciones con otros. Con esto, el tiempo en el que pervive aquello que el hombre desea, teme o espera impacientemente no es extraño a la situación histórica del hombre que piensa y enuncia.

\section{Hombre y palabra}

Al describir la comprensión de la conciencia autoral como uno de los hechos que revolucionaron la historia del estudio de la palabra, Bajtín (1982 [1979]) equilibra las tensiones que atribuye al hombre histórico en su relación con el devenir y las que la palabra expresiva registra en su encuentro renovado con otras. No es posible pensar en palabras sin pensar en la situación de su agencia, sin responsabilizar a sujetos singulares por la ocurrencia de su enunciado.

Bajtín observa que "el sistema de la lengua tiene un carácter netamente potencial con respecto a los enunciados reales y a los hablantes reales" (BAJTíN, 1982 [1979], p. 307). Su crítica ilumina el problema central que presenta el concepto estructuralista de la palabra. Ésta, entendida como elemento en relación inmutable con otros de un sistema comienza a comprenderse como el recurso material necesario en la consecución de una cadena de comunicación interindividual desplegada en complejas (no-lineales, discontinuas) coordenadas de espacio-tiempo. 
La concepción saussureana de palabra entraña una noción de tiempo que la emplaza sobre la plataforma estática y sustituible de los estados de la lengua, en el tiempo de la simultaneidad y la relación opositiva y equilibrada. La palabra bajtineana tiene su emergencia concreta, material e intempestiva sobre la lámina móvil y dinámica del tiempo de la evolución. En definitiva, a la voz que se pronuncia sobre la inmutabilidad que la fuerza de la masa hablante garantiza en el tiempo de la tradición, le sigue la segunda voz bajtiniana. Queda abierto así un debate sobre las formas posibles de relación entre ciencia, ideología y hombre histórico, que recupera la conciencia sobre la creatividad ideológica y la calidad revolucionaria, bivocal y reflexiva de la palabra.

\section{Diálogo de una filosofía autoreflexiva}

Al designar el núcleo libre del texto, Bajtín entiende que la creatividad del estilo en el texto revela la libertad de la personalidad del hombre. El fenómeno de reenvío por el que la creación de lo nuevo se atiene a lo dado mientras pergeña su fuga "no permite ni una explicación causal ni una previsión científica" (BAJTíN, 1982 [1979], p. 298).

Con esto, consideramos necesario describir la relación dialógica que el mismo Bajtín establece entre el campo de la filosofía del lenguaje, la lingüística estructural y la historia literaria. Dicha descripción pondría en evidencia el carácter autoreflexivo de su producción intelectual, y requeriría analizar sus elementos estructurantes organizados en el tiempo de lo representado² de su teoría.

\section{Hombre de responsabilidad ética}

El concepto bajtiniano espacio semiótico común es comprensible a condición de asumirlo espacio en transformación y al sujeto como éticamente responsable de su participación en él.

Frente al sujeto trascendental kantiano, Bajtín propone el principio del sujeto éticamente responsable. Los últimos ecos del asociacionismo saussureano, que postulaba la impotencia de la voluntad individual frente a la tradición de la masa hablante que resguardaba la continuidad de la lengua, comenzaban a ser rebatidos (ALONSO en SAUSSURE, 1945). El problema de la oposición entre el subjetivismo

\footnotetext{
${ }^{2}$ En paráfrasis de las categorías tiempo que representa y tiempo representado, definidas por Bajtín en su desarrollo sobre las interacciones asignables entre el mundo que representa y el mundo representado en los límites de una obra literaria.
} 
idealista del trascendentalismo y el objetivismo abstracto de la tradición estructural debe formularse, como asegura Bertorello (2009), como la expresión de la tercera antinomia de Kant.

El subjetivismo idealista da cuenta de la tesis de la antinomia (la concepción ética). El lenguaje se presenta como el producto de una creación libre y estética. En cambio, el objetivismo abstracto representa la antítesis de la antinomia (la concepción científica). El lenguaje es un producto desligado de sus condiciones de producción, se rige por principios inmanentes. (BERTORELLO, 2009, pp. 145146)

En términos dialécticos, a la tesis sobre la concepción del lenguaje como un producto regido por leyes inmanentes se opuso la antítesis que remite el lenguaje a su realidad, dándole relevancia al acto de la voluntad individual (BERTORELLO, 2009). Por una parte, el subjetivismo idealista, que desconoce el plano del acto histórico-social y, por otra, el objetivismo abstracto, que entiende el lenguaje como el hecho secundario de los usos de un hablante incapaz de modificar las reglas de la lengua. Bajtín (1982 [1979]) y Voloshinov (1992 [1929]) delatan con énfasis los efectos ideológicos de ambas posturas teóricas. A la tesis del sujeto originario y trascendental y la antítesis del objetivismo cientificista, Bajtín responde con la síntesis del sujeto situado, éticamente responsable de los actos de su tiempo y de una conciencia constituida en el espacio de lo interindividual.

\section{Hombre, enunciado y tiempo}

Para Bajtín, el tiempo no es la recta de lo trascendental sino algo análogo a lo que Regine Robin (2012 [2003]) denominó tiempo chirriante; un complejo de discontinuidades, marchas y contramarchas anclados en la realidad material y en su transformación. Las críticas de Bajtín a la concepción kantiana del tiempo como una forma indispensable y trascendental de la percepción y la representación lo conectan con el principio foucaultiano del sujeto de la historia (2011 [1969]). Bajtín no considera el tiempo como forma trascendental precisamente porque el sujeto, tal como diría Foucault (2011 [1969]) años después, debe abandonar el apacible refugio que le otorga la idea de un pacto de complicidad con el mundo. La imagen que la formulación de sujeto originario envía presenta la ficción de uno que habría establecido un acuerdo fundamental con el mundo que lo autoriza a devolverle, en cualquier momento del tiempo, un reflejo fiel.

La descripción de Foucault aparece cuestionando, en definitiva, la supresión de la realidad del discurso y del acontecimiento de su emergencia. En la misma dirección, 
Bajtín se niega a entender la situación histórica del hablante como una réplica de su condición originaria. La abarca, en cambio, como un acto atribuible a sujetos con posiciones enunciativas interactuantes en su realidad más auténtica. "La propuesta superadora del sujeto trascendental para pensar en un sujeto situado que no puede apartarse de su responsabilidad valorativa del aquí y ahora" (ARÁN, 2010, p. 15). La complejidad y discontinuidad con las que Bajtín (1989 [1937-1938]) caracteriza al proceso de asimilación del cronotopo histórico real en la literatura, pueden describir las coordenadas de lugar y tiempo del sujeto histórico del enunciado.

\section{El espacio semiótico común}

La resistencia obstinada atribuida a los géneros antiguos bajo los efectos del tiempo que desplaza, destruye y construye es asimilable a la actitud del sujeto trascendental en relación con el tiempo que trastoca la armonía de lo dado. En este punto, la interpretación kantiana anticiparía que la acción del tiempo no podría romper el pacto de complicidad original entre el sujeto y el mundo. Bajtín ofrece una respuesta diferencial: el tiempo en devenir, lo inminente, relacionado con los deseos y las exigencias de los otros, anuncia el final de la armonía entre el pensamiento y el enunciado del hombre solitario. La desatención idealista de la dimensión ideológica de la historia es sentenciada por Foucault como "el lugar del reposo, de la certidumbre, de la reconciliación, del sueño tranquilizador" (FOUCAULT, 2011 [1969], p. 27). Por lo tanto, la resistencia de lo que está por ser contestado es siempre resistencia a la intempestiva ocurrencia de la respuesta. Es decir, la actitud resistente parte del reconocimiento de la alteridad y del transcurso inevitable del tiempo de la comunicación.

La condición mínima para comprender la noción de cadena de comunicación discursiva reside en captar la naturaleza de la relación asignada entre el hombre y el medio semiótico común. Bajtín afirma, con esta inquietud, que "un acto humano es un texto en potencia y puede ser comprendido tan sólo dentro del contexto dialógico de su tiempo" (BAJTÍN, 1982 [1979], p. 298). Aquí aparece comprendida en toda su magnitud el concepto de situación y su relación con el desarrollo de la cadena textual. La réplica consciente, la postura llena de sentido, son actos humanos abordables por un análisis sociológico que indague en su integración a un contexto dialógico con otros actos humanos. La cuestión natural en Bajtín es la cuestión de los polos: lo irrepetible frente a lo dado, la situación frente a los marcos creados.

Con lo dicho, el enunciado es el punto de partida del estudio de todas las disciplinas toda vez que abreva en el hombre. En esto pensaba Bajtín al considerar 
que "una sola palabra también puede llegar a ser bivocal si representa una abreviatura del enunciado". (BAJTíN, 1982 [1979], p. 299)

\section{La temporalidad de las fronteras del enunciado y la cultura popular}

Los cambios de los sujetos discursivos, la función expresiva de la palabra en la comunicación y el contacto directo experimentado entre el enunciado y la realidad transcurren en segmentos de duración con principio y fin. Éstos se sobreponen unos a otros y conforman lo que Bajtín define como el tiempo que representa.

En su descripción de las formas y rituales del carnaval en la Edad Media y el Renacimiento, Bajtín distingue el carácter durativo de las fronteras del carnaval de su carácter espacial. La festividad popular, asegura, sucede como un "retorno efectivo y completo -aunque provisorio- a la edad de oro de Saturno" (BAJTín, 1987 [1971], p. 13) o como "una huida provisional de los moldes de la vida ordinaria" (13) (las cursivas son mías).

Ahora bien, al interior del período temporal del carnaval desplegado sobre el tiempo que festeja ${ }^{3}$, toma forma el tiempo de lo festejado, que instala el principio de la regeneración y del trasvasamiento de las fronteras rituales (de principio y fin). La festividad popular se ríe de ellas, las olvida alegremente durante el tiempo de lo festejado, pero al cabo de su capitulación, el orden temporal devuelve las jerarquías y los finales al lugar que ocupaban antes del período de carnaval. Esta es la clave de lectura de una afirmación de principio: "durante el carnaval no hay otra vida que la del carnaval" (BAJTíN, 1987 [1971], p. 13) (las cursivas son mías).

\section{La temporalidad en el cronotopo}

No pretendemos abordar la dimensión temporal del crotonopo ignorando la espacial, siempre que, como Bajtín nos confirma, "están ineludiblemente vinculadas" (BAJTÍN, 1989 [1937-1938], p. 409). Sin embargo, observamos, junto a Pampa Arán (2010, p. 17), que "el principio rector del cronotopo es el tiempo porque éste guía toda la perspectiva evolutiva". La autora recupera a Bajtín cuando reflexiona sobre el requerimiento de

\footnotetext{
${ }^{3}$ Paráfrasis de las categorías tiempo que representa y tiempo representado. De la pregunta sobre el punto del espacio temporal desde el que el autor observa el acontecimiento que está representando (Bajtín, 1989 [1937-1938]), extraemos la inquietud sobre el punto espacio temporal con el que asume un analista del discurso el enunciado y sus relaciones con sus marcos.
} 
(...) "saber ver el tiempo, saber leer el tiempo en la totalidad espacial del mundo y, por otra parte, percibir de qué manera el espacio se llena no como un fondo inmóvil, como algo dado de una vez y para siempre, sino como una totalidad en el proceso de generación, como un acontecimiento: se trata de saber leer los indicios del transcurso del tiempo en todo (...)." (BAJTÍN en ARÁN, 2010, p. 17).

En su descripción del carnaval medioevo, Bajtín asegura que éste era entendido por sus participantes como "el triunfo de una especie de liberación transitoria" (BAJTÍN, 1987 [1971], p. 15). El factor que vuelve necesario pensar en los límites rituales del tiempo del carnaval es su calidad de voz de respuesta en el tiempo de la comunicación discursiva. En este sentido, consideramos el espacio del carnaval emplazado en el tiempo de lo festejado, en el umbral del porvenir incompleto y la regeneración, pero sin olvidar que su duración inscribe un segmento del tiempo que representa $y$ festeja.

El espacio semiótico común en el que son formadas las conciencias también es el medio de emergencia e interacción de proyectos ideológicos. Tales proyectos entran en competencia por la concreción de sus intenciones. En ese marco, son delimitadas voces que adoptan modalidades estratégicas en búsqueda de la concreción de sus objetivos y permanecen expectantes al devenir de la respuesta de un otro. La categoría estrategias de inversión, acuñada por Georges Balandier (1994 [1992]) en su reflexión antropológica sobre la escenificación del poder en el espacio público, ilumina este asunto de una manera singular. La descripción bajtiniana de la festividad popular la designa como un evento de ilimitada libertad en el que las jerarquías del orden social son elididas. Bajtín se pronuncia desde el sustrato de totalidad del tiempo del carnaval, donde el contenido de la respuesta olvida la primera voz que lo interpeló, su calidad misma de respuesta y la voz que le seguirá en el tiempo. La propuesta de Balandier representa un insumo para comprender el tiempo de la cultura popular (cómico, positivo) sin perder de vista su inclusión en el tiempo más amplio de la comunicación discursiva (delimitante, sobre fronteras).

Según el autor, los sacerdotes y miembros de la nobleza plegados a las celebraciones como la del Asno o de los Locos no resignaban ni olvidaban su condición de portavoces autorizados de la voz oficial. Conscientes del tiempo de su interacción con la cultura popular, oponían "una humildad teatral, y momentánea, al lujo y a la suntuosidad de su existencia habitual" (BALANDIER, 1994 [1992], p. 39). Balandier asimila el ritual del carnaval a una estrategia de inversión del proyecto del orden oficial.

La inversión carnavalesca consiste, por un lado, en el mecanismo que permite "romper las censuras y convenciones en favor de la fiesta" (99). Sin embargo, por otro lado, en la prueba de que "no existe otra alternativa al orden establecido por la 
ley que la befa, lo arbitrario y el acecho del caos (87). Balandier recupera el interés de la antropología política moderna por los rituales de inversión que las instituciones del pasado practicaban en refuerzo de la norma.

Desde esta perspectiva, el desorden del carnaval es la escenificación del orden bebiendo las fuerzas que lo revigorizan (BALANDIER, 1994 [1992]). El carnaval toma forma de una subversión cíclica y codificada y, al mismo tiempo, festiva. Libera por medio del juego, pero no socaba las instituciones (BALANDIER, 1994 [1992]). El desplazamiento simbólico practicado durante la Fiesta del Asno asocia un burro doméstico a Jesucristo o a un príncipe. La representación magnifica la misma estructura social imperante, sólo que al inverso: la única alternativa a la nobleza es aquella en la que otra nobleza se impone, en períodos rituales, con el sonido de tres rebuznos.

\section{La Fiesta del Asno, Esaú 'el profano' y el carnaval brasilero. Estrategias de inversión}

Nietzsche (1981 [1883]), en la cuarta parte de Así babló Zaratustra, narra el diálogo abierto entre Zaratustra y un grupo de fieles que ofrecía sus liturgias al asno en el templo religioso. Dos de las contestaciones a los reproches del primero resultan cardinales para comprender el ritual de inversión por el cual la fiesta popular revitaliza el orden. El Concienzudo del espíritu le respondió a Zaratustra: "lo cierto es que en esta figura es en la que Dios me parece máximamente creíble" (420). El viejo papa, por su parte, contestó: "ies preferible adorar a Dios bajo esta forma que bajo ninguna! Medita sobre esta sentencia, noble amigo: enseguida adivinarás que en tal sentencia se esconde sabiduría" (419).

Zaratustra había interpelado a los fieles por primera vez cuando "gritó más fuerte que el propio asno y se lanzó de un salto en medio de sus enloquecidos huéspedes (...)". Más adelante, el Concienzudo del espíritu lo interrogaría: "¿No le gusta a un sabio perfecto caminar por los caminos más torcidos? La evidencia lo enseña, oh Zaratustra, - itú evidencias!" Nietzsche (1981 [1883], p. 421). Es a partir del transcurso del no-orden de la Fiesta del Asno que toma predominio el diálogo con una voz que sobrepasa el rebuzno del rey-burro.

En el libro de la Biblia, el Libro de Génesis relata la parábola Esaú, el profano. Esaú y Jacob, hijos de Isaac y Rebeca, simbolizan respectivamente al mundano y al espiritual. Durante la época de los Patriarcas, el hijo primogénito gozaba del favor de su familia y de la bendición de su padre. Esaú, el mayor, al regreso de una larga excursión de caza en el campo, encontró a su hermano cocinando y, aún mereciendo 
una doble porción, vendió su primogenitura por un plato de lentejas. "Él comió y bebió, y se levantó y se fue. Así menospreció Esaú la primogenitura" (Génesis 25:34, Sociedades Bíblicas Unidas). En el Nuevo Testamento, el capítulo noveno del libro de Lucas, presenta una situación en la que Jesús, luego de anunciarles su muerte y resurrección indica a sus apóstoles: "Si alguno quiere venir en pos de mí, niéguese a sí mismo, tome su cruz cada día y sígame" (LUCAS 9:23, Sociedades Bíblicas Unidas). Tomando una opción contraria, Esaú se había afirmado a sí mismo negando el orden jerárquico establecido por una tradición espiritual. Sin embargo, no estableció con esto un principio de flexibilidad del Patriarcado. Al contrario, reaseguró su continuidad invariante. Al colocar su primogenitura al mismo nivel que un plato de lentejas, revaloriza el privilegio del primogénito en relación con el beneficio mundano de aquel que comió, bebió y se fue. La consigna cristiana de la negación de sí mismo viene a traducirse en el acto de negar la negación del orden superior y ofrecerla como el alimento del mismo orden.

En Brasil, el domingo, lunes y martes que anteceden inmediatamente a Cuaresma, es festejado el carnaval de las escolas do samba. Roberto DaMatta (1997, 2000) distingue el tiempo del carnaval brasilero del tiempo del Dia da Pátria (desfile militar cada 7 septiembre, conmemorativo de la independencia nacional). El del carnaval es cósmico y cíclico, mientras el del Dia da Pátria es un tiempo histórico y documentado. Este último rito, organizado por el Ejército, la Marina y la Fuerza Aérea, actualiza en todos sus niveles las distinciones jerárquicas. Los desfiles de carnaval son organizados por la comunidad de las zonas más pobres y marginalizadas de la sociedad brasilera. Sin embargo, como señala DaMatta (1997), las escolas son ubicadas en libre competición. El desfile carnavalesco presenta, así, algunas paradojas.

El foco en las cosas dislocadas e insólitas remite a aquellas correctas y prescritas. DaMatta, en relación con esto, subraya que "es en el carnaval donde permitimos la confusión de las reglas de la jerarquía" (137). De esta forma, la vida social pequeño-burguesa brasilera queda invertida pero comparte con su inversión una misma estructura. El vida carnavalesca queda filtrada por motivaciones como deber divertirse y deber aventurarse. Estas son proposiciones paradojales, porque son opuestas a las del mundo diario. Durante los días de esta fiesta popular, sabemos que la diversión y la dislocación no son posibilidades sino obligaciones, pero las vivimos como determinadas en un estado de plena libertad. "Es como en el cine, donde sabemos que el Bien deberá triunfar sobre el Mal, pero acompañamos la farsa hasta el final" (DAMATTA, 1997, p. 139). La alternativa a lo cotidiano es planteada pero inmediatamente controlada. 
El tiempo del carnaval, pese a olvidar alegremente las fronteras negativas de los rituales oficiales con principio y fin, no disocia sus coordenadas de las del tiempo de la comunicación discursiva, donde transcurren los cambios de sujetos discursivos y la interacción de posiciones enunciativas. Por el contrario, adopta la forma de una segunda voz en respuesta a la voz oficial, de resistencia a la estabilidad de lo dado de suyo, los pronósticos y las clasificaciones.

\section{DEFINICIÓN SOCIOLÓGICA DE LA CONCIENCIA}

\section{Conciencia y tiempo}

Uno de los errores que Voloshinov (1992 [1929]) remarca del idealismo y el objetivismo abstracto está relacionado con la definición subjetivista de la conciencia, que refunde entre sí todas las definiciones objetivas de la conciencia. Al establecer que "una definición objetiva de la conciencia sólo puede ser sociológica", Volonishov (1992 [1929], p. 36) sugiere que el carácter intersubjetivo de la constitución de la conciencia individual es, principalmente, el dato objetivo que reclama atención.

La conciencia comprende la voz ajena siempre que la objetiva. "¿No será que un determinado grado de objetivación sea una condición necesaria de todo estilo? (...). Tal vez cada escritor sea siempre 'dramaturgo'", supone Bajtín (1982 [1979], p. 301): cualquier discurso aparece en su obra distribuido en voces ajenas. El hablante, el hombre que responde por su enunciado, es aquel que objetiva el discurso ajeno y reconoce, al mismo tiempo, la alteridad en el enunciado propio. La conciencia del enunciado propio, por lo tanto, no es menos conciencia de la alteridad que la conciencia del discurso ajeno. "El saber expresarse a sí mismo implica hacer de uno mismo el objeto para el otro y para uno mismo" (BAJTín, 1982 [1979], p. 301). La teoría bajtineana del enunciado insiste de manera persistente en la realidad de la conciencia.

\section{Comprensión dialógica}

En el tiempo de la comunicación discursiva, se inserta la comprensión como su momento dialógico. La comprensión, que actualiza la relación de la conciencia con el espacio semiótico común, es un acto con efectos dinámicos y evolutivos, como la voz carnavalesca popular. El momento de realización del proyecto de un sujeto discursivo produce el efecto de una respuesta creativa, la emergencia de una voz 
que reconoce la multiplicidad de respuestas posibles a la voz ajena (divergencia, acuerdo, réplica, exclusión, etc.) y otorga realidad a una. Esto explica el nivel específico en el que Bajtín ubica la participación de aquel que comprende en el diálogo, definido "según el enfoque de la comprensión o la investigación" (BAJTíN, 1982 [1979], p. 318). Identificar el nivel específico de la participación de una comprensiónrespuesta supone reconstruir su medio ambiente ideológico.

El nivel específico de la comprensión de la voz carnavalesca queda directamente con los marcos que construye a partir de las voces dichas. Con todo, la comprensión implica un acto de valoración de otros proyectos ideológicos y un acto de contestación con nuevas intenciones.

\section{Comprensión y destinador superior}

En cierto sentido, al comprender, imaginamos. Bajtín asegura que el estatus posible de toda voz que espera comprensión la vincula con un bien supremo, como la verdad, la belleza o el bien (BAJTÍN, 1982 [1979]). Esto debe llamar la atención de toda reflexión que verse sobre la dimensión asignada por Bajtín a la cuestión del tiempo.

En primer lugar, señalaremos que el momento de la comprensión, que hace efectiva la realización del texto que permanecía en su etapa intencional, es entendido por nuestro autor como un acto ocurrido en la interacción de dos conciencias. A lo largo de la cadena de la comunicación discursiva, la intención mantenida al momento del proyecto se actualiza en futuros enunciados porque es actualizado el medio ambiente social de las conciencias en diálogo.

Es precisamente mediante la relación dinámica entre el bien supremo y la alteridad con la que Bajtín propone superar la relación opositiva ley inmutable-masa bablante del estructuralismo. En pocas líneas, el autor acusa su postura, positiva y crítica a la vez, al asegurar, por una parte, que "al seleccionar las palabras partimos de la totalidad real del enunciado que ideamos" (BAJTÍN, 1982 [1979], p. 276) y, por otra, que "las solemos tomar de otros enunciados, y ante todo de los enunciados afines genéricamente al nuestro" (BAJTíN, 1982 [1979], p. 277).

\section{Destinador Superior y Tiempo}

En La cultura popular en la Edad Media y el Renacimiento, Bajtín (1987 [1971]) advierte sobre la especificidad del sentido del carnaval en conexión con los objetivos superiores de la existencia. La vida oficial y la vida carnavalesca, que 
encarnaban la primera voz seria y la segunda festiva incluidas a la cadena de la comunicación de la cultura Europea, se desarrollaban sobre el tiempo que posterga su final ideal.

El tiempo se extiende, desdoblado, al interior de las fronteras de la vida oficial y, a la vez, sobre las fronteras que la separan de la vida del carnaval y lo remiten al horizonte del bien supremo. En palabras de Bajtín, integrado al Seminario Kantiano, la sanción de la segunda voz no emana del mundo de los medios y condiciones indispensables, "sino del mundo de los objetivos superiores de la existencia humana, es decir, del mundo de los ideales" (BAJTíN, 1987 [1971], p. 14).

La acción regeneradora de la risa es, en sí misma, positiva. Ahora bien, como vimos, la renovación incesante que se ríe de la muerte (BAJTíN, 1987 [1971]) niega, en el tiempo de la comunicación discursiva, la acción seria del tiempo a la vez que la revigoriza.

El tiempo de la segunda voz conclusiva es un tiempo ritual que comienza y finaliza. El punto común donde los planos del tiempo se unifican es concentrado en el hombre histórico, que actúa y reacciona, proyecta ideales y sanciona proyectos ajenos. Así, la emergencia de la segunda voz del carnaval se inserta en el tiempo de las posiciones enunciativas, de los acuerdos y las polémicas, del trabajo y de la vida íntima.

Podemos asumir, a esta altura, lo que Bajtín postuló recurrentemente: el sentido posible es el sentido de la vida del hombre que transcurre en el momento liminar entre la conclusividad del otro y la emergencia de sí.

\section{EL LUGAR DEL OTRO Y LOS MARCOS}

Como nos recuerda Pampa Arán (2010), Bajtín enfatiza en la bistoria de las alteraciones de los proyectos. El encuadre en que el autor ubica a la temporalidad no podría incluir los objetivos superiores del enunciado sin considerar la presencia determinante de una constelación de enunciados ajenos dados y en devenir.

A esto nos envía la formulación sobre "la inclusión del futuro que concluye la plenitud del tiempo en las imágenes" (ARÁN, 2010, p. 15). El sujeto de la autoobjetivación que visitamos en páginas anteriores se desliza en el mundo de los signos ideológicos, desde donde "observa el dinamismo que el paso del tiempo opera sobre el espacio y los hombres" (ARÁN, 2010, p. 17). La biografía del sujeto y su posición enunciativa penetran el tiempo de la cultura configurándolo, conformando la base material e histórica de su comprensión. 
Las condiciones para el cambio, en la cadena temporal de la comunicación discursiva, preceden a la irrupción de una nueva comprensión-respuesta, que transforma la economía de enunciados en la que emerge, que crea a partir de lo dado y se desliza en un espacio de interacción no- estático. En palabras de nuestro autor, "el hablante mismo cuenta con esta activa comprensión preñada de respuesta" a la vez que "él no es un primer hablante, quien haya interrumpido por vez primera el eterno silencio del universo" (BAJTín, 1982 [1979] p. 258).

La primera voz "quiere una contestación, participación, objeción, cumplimiento, etc." (BAJTÍN, 1982 [1979], p. 258). La responsabilidad ética del hombre histórico consiste, entonces, en reconocer los marcos de su enunciado. El otro que replica, interroga, disiente o acuerda, crea los marcos de mi enunciado. Marcos evaluativos, delimitantes, provenientes del otro sujeto discursivo en la cadena de comunicación. Es el mismo Bajtín quien planteó que, en el campo de los estudios de la lingüística y la historia literaria de su época, se registraba un terreno virgen: el del estudio "del problema del segundo sujeto que crea otro texto como marco (comentario, evaluación, objeción, etc.)" (BAJTíN, 1982 [1979], p. 295).

El sujeto no habla irrumpiendo la nada ni creando a pesar de lo dado. "Si tuviéramos que irlos creando (a los marcos) cada vez dentro del proceso discursivo, libremente y por primera vez cada enunciado, la comunicación discursiva habría sido casi imposible" (BAJTíN, 1982 [1979], p. 268) (la aclaración es mía).

De esta manera, Bajtín asimila a la premisa sobre los marcos del enunciado la idea de que el límite de la creatividad ideológica se impone como un límite histórico. Límite originado en la existencia de un espacio común que precede y procede a la aparición de mi enunciado. Pero, sin embargo, límite no restrictivo, de cuyo interior mi enunciado emerge determinado pero contestatario. Límite desplazable por el movimiento de las funciones y los estilos particulares.

\section{La cadena viviente de la comunicación discursiva}

A esta altura, es posible afirmar que el enunciado no existe conclusivo en su proyecto sino en la relación interactiva entre el proyecto y su realización. Reconocer el carácter indisociable de la relación enunciado-comprensión implica asumir su emplazamiento en un espacio semiótico común, agónico, en lucha por el sentido. Entenderemos la naturaleza del concepto bajtiniano de enunciado siempre que asumamos que la significación es determinada en el momento liminar, bivocal, que transcurre entre un enunciado y su respuesta. 
Se vuelve necesario aquí introducir una aclaración sobre el espesor conceptual otorgado a la denominada cadena de comunicación discursiva. Al asegurar que "el texto no es una cosa" (BAJTÍN, 1982 [1979], p. 298), a pesar de que la otra conciencia deba objetivarla para responderle, Bajtín llama la atención sobre el problema de su cosificación. "Un discurso que no se ve como objeto permanece dentro de un diálogo no concluido acerca de un tema determinado" (BAJTíN, 1982 [1979], p. 304-305). El espacio interindividual de creación de sentido, en el umbral de la nueva respuesta, no es, por lo tanto, un espacio de transacción armónica sino de interacción conflictiva, de relación agónica y transformadora.

Allí debemos encuadrar la afirmación de Bajtín de que "el acto no puede ser comprendido fuera de su expresión sígnica (motivos, objetivos, estímulos, grado de conciencia) que nosotros recreamos" (BAJTíN, 1982 [1979], p. 305). El sentido no resulta del intercambio de cosas o de la relación predictiva de elementos de un sistema. Aparece, en cambio, en la actualización que un enunciado realiza de los marcos creados en una esfera dada de la comunicación discursiva.

La cuestión de los marcos opera, en la obra de Bajtín, como el elemento que explica el carácter ideológico de la creatividad del hombre en la historia. "El objeto mismo de su discurso se convierte inevitablemente en un foro donde se encuentran opiniones de los interlocutores directos o puntos de vista, visiones del mundo, tendencias" (BAJTÍN, 1982 [1979], p. 284).

\section{Sobre las fronteras del enunciado y el tiempo}

A este punto, nos hemos aproximado indirectamente a uno de los elementos cuya comprensión aporta a la localización del tiempo y lo temporal en la Estética de la creación verbal: la relación entre las fronteras del enunciado y lo histórico. El tratamiento del tema impone ubicar el foco en la manifestación fenomenológica de lo que Bajtín llama frontera. Nos referimos al acto específico de la alternación de la expresividad.

La situación dialógica de dos hablantes incluidos en una esfera de la comunicación significa las disputas entre objetivos discursivos y la presencia determinante de una tercera voz o destinador superior. En ese orden, la alternación no es producida entre unidades que comienzan solapadas sobre unos finales o concluidas sobre el comienzo de sus respuestas. El cambio de sujetos discursivos que establece las fronteras de los enunciados es un hecho producido en el tiempo de la comunicación, que es el tiempo de la sucesión. Entre la conclusividad de la primera voz y la toma de la palabra de la segunda se abren pausas, intervalos de duración en los que una voz interpela y la otra es interpelada. "Las pausas que se dan entre los enunciados no tienen un 
carácter gramatical sino real" (BAJTÍN, 1982 [1979], p. 263). La puesta en relieve de la pausa, como elemento positivo y ligado esencialmente a los enunciados en interacción, nos recuerda el lugar central designado por Bajtín a la historia y a los transcursos en su teoría de la acción del hombre en la cultura y la fecundidad del debate devuelva la mirada sobre ese centro.

\section{CONCLUSIÓN}

Es importante recuperar algunos conceptos que tienden un lazo con la noción cardinal de tiempo que, brevemente, hemos intentado desentrañar de la propuesta bajtiniana.

La tradición lingüística, que establece que las unidades de la lengua reestablecen la materia vieja conformando un estado de la lengua que sustituye al anterior, insiste en que lo que importa no es el acto de sucesión y cambio, sino el hecho sincrónico del estado dado al margen de la historia. Como nos recuerda Aniceto (2013) el estado de la lengua en un momento dado es estudiado como un estado que contiene un factor bistórico condensado, depositado por la tradición en la lengua, pero aislado del tiempo del cambio. La teoría crítica de Bajtín desplaza la mirada a las relaciones entre momentos dialógicos de la comunicación discursiva desarrollada en la historia, tan dada como incompleta.

El lugar del otro instaura con el propio un mero contacto de contigüidad y nexo, sino de situación espacio temporal y de interacción en una esfera común. Afirmando que "el signo sólo puede surgir en un territorio interindividual", Voloshinov (1992 [1929], p. 35) se expresa en consonancia, al hacer referencia al terreno de dos individuos socialmente organizados. Un estudio comprometido con un abordaje exhaustivo del papel del tiempo transformador debe partir del supuesto de que el medio semiótico común es la base del despliegue de las funciones de los signos ideológicos (VOLOSHINOV, 1992 [1929]). El tiempo de las relaciones dialógicas, desde esta óptica, nos remite al tiempo de la interaccion agónica entre enunciados con proyectos estratégicos.

\section{REFERENCIAS}

ANICETO, P. D. (2013). El factor histórico de la lengua y el tiempo de los discursos. Revista Forma y Función, Departamento de Linguística de la Facultad de Ciencias Humanas, Universidad Nacional de Colombia, Bogotá, v. 26, n², pp. 11-40. 
ARÁN, P. O. (2010). "Las cronotopías literarias en la concepción bajtiniana. Su pertinencia en el planteo de una investigación sobre narrativa argentina contemporánea". En: Arán, P. O. (coord.), Interpelaciones: bacia una teoría crítica de las escrituras sobre dictadura y memoria. Córdoba: Centro de Estudios Avanzados, pp. 13-30.

BALANDIER, G. (1992). El poder en escenas. De la representación del poder al poder de la representación, trad. Manuel Delgado Ruiz. Barcelona: Paidós, 1994.

BAJTÍN, M. (1979). Estética de la creación verbal, trad. Tatiana Bubnova. México: Siglo XXI, 1982.

BAJTÍN, M. (1971) La cultura popular en la Edad Media y en el Renacimiento. El contexto de Francois Rabelais, trad. Julio Forcat y César Conroy. México, D.F.: Alianza Editorial, 1987.

BAJTÍN, M. (1937-1938). Las formas del tiempo y el cronotopo en la novela. En: Bajtín, M., Teoría y estética de la novela, trad. Helena S. Kriúkova y Vicente Cazcarra. Madrid: Taurus, 1989, pp. 237-409.

BERTORELlO, A. (2009). Bajtín: Acontecimiento y Lenguaje. Revista Signa, n 18, pp. 131-157.

BOURDIEU, P. (1985). ¿Qué significa hablar?, trad. Esperanza Martínez Pérez. Madrid: Akal, 2001.

CASETTI, F. (1980). Introducción a la semiótica. Barcelona: Fontanella.

DAMATTA, R. (1997). Carnavais, malandros e beróis. para uma sociologia do dilema brasileiro. Rio de Janeiro: Rocco.

DAMATTA, R. (2000). Individualidade e liminaridade: considerações sobre os ritos de passagem e a modernidade. Mana, v. 6, n 1, pp. 7-29.

FOUCAULT, M. (1969). La arqueología del saber, trad. Aurelio Garzón del Camino. Buenos Aires: Siglo veintiuno, 2011.

NIETZSCHE, F. (1883). Así babló Zaratustra, trad. Andrés Sánchez Pascual. Madrid: Alianza, 1981.

ROBIN, R. (2003). La memoria saturada, trad. Victor Goldstein. Buenos Aires: Waldhuter Ediciones, 2012.

SAUSSURE, F. de. (1915). Curso de lingüística general, trad. Amado Alonso. Buenos Aires: Losada, 1945.

VOLOSHINOV, V. N. (1929). El marxismo y la filosofía del lenguaje, trad. Tatiana Bubnova. Madrid: Alianza editorial, 1992.

Recebido: 27/07/2015

Aceito: 07/10/2015 